ADALAH : Buletin Hukum \&

Keadilan

Buletin Hukum \& Keadilan

\title{
Iklan Menyesatkan (Deceptive Advertisement) Dalam Hukum Perlindungan Konsumen
}

\author{
Indra Rahmatullah*
}

Baru-baru ini sebagai konsumen dikagetkan dengan merebaknya berita bahwa ada salah satu produk Susu Kental Manis (SKM) kalengan yang ternyata menurut penyelidikan Badan Pengawas Obat dan Makanan (BPOM) tidak mengandung susu murni dan tidak cocok dikonsumsi untuk anak-anak dan balita, melainkan sebagai pelengkap sajian saja. Padahal SKM tersebut merupakan merek terkenal selama puluhan tahun yang sudah sangat familiar di tengah-tengah masyarakat ternyata berbeda dengan kandungan isi aslinya yang dipasarkan sebagai SKM murni.

BPOM dalam rilisnya kemudian merekomendasikan kepada produsen produk tersebut untuk segera melepaskan iklan terhadap produk Susu Kental Manis dan menarik produknya yang masih dijual bebas di pasaran. Peristiwa ini jelas sangat merugikan masyarakat sebagai konsumen karena dalam kurun waktu yang lama, masyarakat disuguhi produk yang tidak sesuai dengan iklan yang diinformasikan.

Dalam perspektif hukum perlindungan konsumen, masyarakat diposisikan sebagai konsumen yang hak-haknya dilindungi oleh Undang-Undang Nomor 8 Tahun 1999 tentang perlindungan konsumen. Konsumen mendapatkan perlindungan hukum

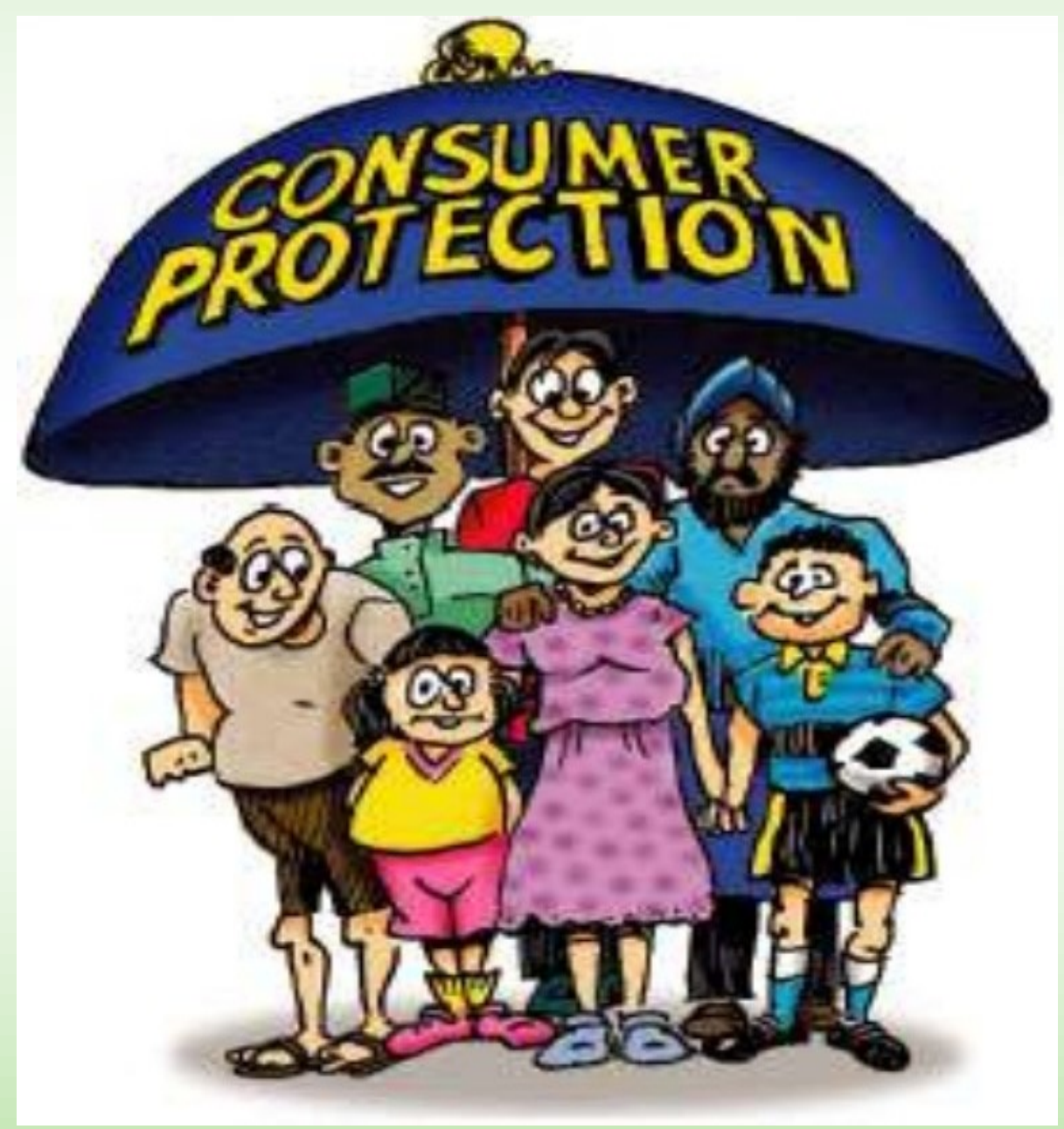

karena pada posisi aslinya, ada gab antara konsumen dan produsen di mana konsumen berada pada posisi lemah dikarenakan kurangnya pengetahuan dan informasi yang didapatkannya.

Dalam Undang-Undang Perlindungan Konsumen diatur secara jelas hak-hak konsumen yang harus dihormati dan dipenuhi oleh setiap produsen dalam Pasal 3 di mana salah satunya adalah "konsumen berhak atas informasi yang benar, jelas, dan jujur mengenai kondisi dan jaminan barang dan/atau jasa" atau konsumen berhak mendapatkan informasi yang sejelas-jelasnya dari produsen-the right to be informed (Badrulzaman, 1986: 61). 
Produsen SKM yang ternyata menurut BPOM produknya tidak sesuai dengan iklan yang sebenarnya, maka dapat dipastikan telah melanggar hak konsumen untuk memberikan informasi yang benar, jelas dan jujur sehingga menurut Undang-Undang dapat dikenakan sanksi pidana karena dengan sengaja telah mengelabui konsumen serta menyampaikan iklan yang menyesatkan kepada masyarakat (Deceptive Advertisement).

Iklan yang menyesatkan menurut Handler adalah jika representasi tentang fakta dalam iklan adalah salah, yang diharapkan untuk membujuk pembelian barang yang diiklankan, dan bujukan pembelian tersebut merugikan pembeli, serta dibuat atas dasar tindakan kecurangan atau penipuan (Handler, 1972: 475). Oleh karena itu, untuk melindungi hak-hak konsumen sebagaimana yang diamanatkan oleh UndangUndang, maka iklan produkproduk kepada masyarakat dilarang disampaikan dengan menggunakan cara: a. Mengemukakan hal-hal yang tidak benar (false statement); b. Mengemukakan hal-hal yang menyesatkan atau tidak proporsional (mislead statement), c. Menggunakan opini subjektif yang berlebihan tanpa didukung fakta (puffery) (Shofie, 2005: 154).

Perwujudan regulasi tersebut merupakan bentuk perlindungan hukum yang erat kaitannya dengan aspek keadilan, karena pada hakikatnya tujuan adanya hukum adalah mencapai keadilan. Maka dari itu, adanya perlindungan hukum merupakan salah satu medium untuk menegakkan keadilan yang salah satunya penegakkan keadilan di bidang ekonomi (Dimyati, 2014: 342343).

Di samping ketentuan perangkat hukum sebagai rambu-rambu, tentu saja harus ada etika yang wajib menjadi platfrom dalam memberikan iklan dengan memperhatikan asas-asas umum kode etik perikalanan yaitu: a. Iklan harus jujur, bertanggungjawab dan tidak bertentangan dengan ketentuan hukum yang berlaku; $b$.
Iklan tidak boleh menyinggung perasaan dan atau merendahkan martabat agama, tata susila, adat, budaya, suku dan golongan; dan c. Iklan harus dijiwai oleh asas persaingan yang sehat (Nasution, 41: 2012).

\section{Pustaka Acuan:}

* Penulis adalah Dosen Hukum Bisnis Fakultas Syariah dan Hukum UIN Syarif Hidayatullah Jakarta.

Undang-Undang Nomor 8 Tahun 1999 Tentang Perlindungan Konsumen.

Badrulzaman, Meriam Darus. Perlindungan Terhadap Konsumen Dilihat dari Sudut Perjanjian Baku, dimuat dalam "Hasil Simposium Aspek-Aspek Hukum Masalah Perlindungan

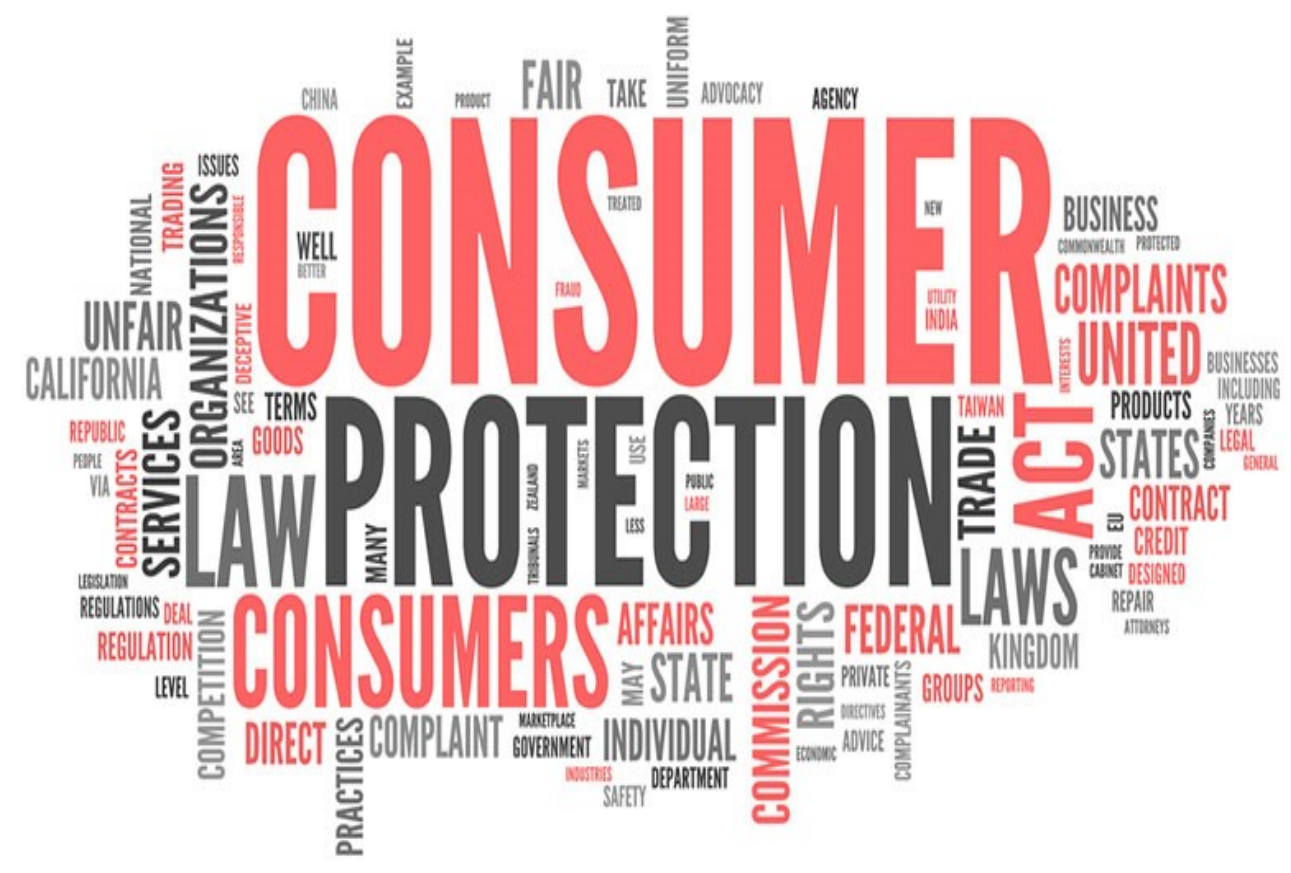

